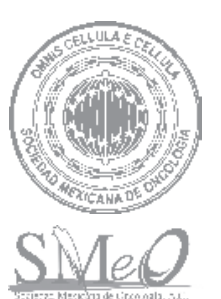

SOCIEDAD MEXICANA DE ONCOLOGÍA, A.C.

ORIGINAL ARTICLE

\title{
Clinical Genetics: Basic Concepts for Oncology Practice
}

\section{Clara Ibet Juárez-Vázquez ${ }^{1, *}$, Ricardo Alejandro Lara-Aguilar ${ }^{1}$, Francisco Javier Ochoa-Carrillo ${ }^{2}$ and Herbert García-Castillo ${ }^{1}$}

${ }^{1}$ Fundación Vida en Genoma A.C., ${ }^{2}$ Instituto Nacional de Cancerología and Hospital Ángeles del Pedregal; Mexico City, Mexico

Received for publication: 10 December 2016; accepted for publication: 25 February 2017

Available online: 14 July 2017

\section{KEYWORDS}

Genetics concepts;

Genetics terms;

Genetic counseling;

Hereditary cancer
Abstract Hereditary cancers are common in clinical oncology 5-10\% of all diagnosed neo: plasms are estimed to be hereditary cancer. Therefore, careful study of the family history, as well as knowledge of the basic principles of genetics is required to address this type of patient. The purpose of this article is to offer basic genetics concepts as a useful tool in oncology clinical practice with practical examples, as well as to justify why a genetics specialist should be part of the multidisciplinary team in patients with a suspected hereditary oncologic condition. (creativecommons.org/licenses/by-nc-nd/4.0/).

*E-mail for correspondence: clarajuarez@lifeingenomics.com (C.I. Juárez-Vázquez) 


\section{INTRODUCTION: PRINCIPLES OF INHERITANCE}

Each trait that Mendel identified in pea plants, such as shape, color, size, etc., corresponds to the expression of a different gene. The phenotype refers to characteristics we observe (morphological, physiological or biochemical), such as the eye color, whereas the genotype is the genetic constitution. The expression and interaction of the genotype with the environment enable the phenotype. As an example, we can mention eye color, which corresponds to the phenotype, whereas the genotype refers to the variants of each gene that influences the determination of this trait.

The term "gene" is defined as a specific DNA fragment or sequence that determines a trait ${ }^{1,2}$; the gene is the fundamental unit of inheritance ${ }^{3}$, and each gene's different versions are known as "alleles" (alternative forms of a gene). For example, the EYCL3 gene is one of the genes that determine the eye color in humans ${ }^{4}$, and there are two alleles for this gene: one for the blue (no brown) and one for the brown eye color.

All genes have a specific position within a chromosome, with this location being known as "locus"; the EYCL3 gene is at $15 q 11.2$, which would translate as chromosome 15 , long arm (q), band 11.2. This locus can be located by the allele for brown or blue (no brown) eye color ${ }^{4}$.

The basic structure of a gene is made up by variable sized DNA regions that encode for specific amino acids in the protein called "exons", while those regions in genes that do not encode for any amino acid are known as "introns" (Fig. 1) $)^{5}$.

\section{HOMOZYGOTE AND HETEROZYGOTE: EQUAL AND DIFFERENT ALLELES}

When both alleles in a locus are equal they are "homozygotes", and when they are different from each other they are known as "heterozygotes". In the eye color example, the brown color allele (B) dominates over the blue (no brown) color (b); this way, when a pair of different alleles $(\mathrm{Bb})$ are present (heterozygocity), only the physical trait encoded by the dominant allele will be observed, i.e. brown eyes; conversely, blue-eyed (no brown-eyed) people would be homozygous for allele $b(b b)$.

It should be noted that the above occurs as long as there is a specific combination of EYCL3 and other genes' alleles, since eye color is a polygenic trait that is influenced by several genes that interact with the EYCL3 gene.

\section{EXAMPLE APPLIED TO ONCOLOGY}

\section{Cytochrome CYP2D6}

Cytochrome P450 is a family of enzymes in charge of metabolizing certain drugs. Among them, the enzyme product of the CYP2D6 gene metabolizes most parts of tamoxifen to convert it into its active metabolite, endoxifen. Most people normally metabolize tamoxifen; however, those who are homozygous for allele 4 (CYP2D6*4/CYP2D6*4) display the slow metabolizing phenotype and, therefore, tamoxifen metabolizes too slowly into endoxifen, which causes the treat- ment to be inefficacious. These patients are candidates to aromatase inhibitors such as letrozole rather than to tamoxifen. Heterozygotes with the CYP2D6*1/CYP2D6*4 genotype are expected to exhibit the intermediate metabolizer phenotype and to have reduced endoxifen levels, which implies clinical inefficacy. In the Mexican population, a frequency of $3.1 \%$ of CYP2D6*4 slow metabolizers has been found, as well as $20.7 \%$ of intermediate metabolizers, heterozygous for CYP2D6*4 (i.e. CYP2D6*1/CYP2D6*4) .

The P450 cytochrome is an example of a gene that follows a Mendelian pattern of inheritance, where both alleles are expressed in the heterozygous status; i.e. it is a gene with a co-dominant pattern of inheritance. There are ongoing studies with large numbers of patients in order to deter: mine if this pharmacogenetic study should be applied to all patients in routine clinical practice ${ }^{7}$.

\section{TYPES OF INHERITANCE}

In the human species, chromosomes are classified as sexual chromosomes (X, Y) and autosomes (pair 1 to 22), which are identical between both genders; for this reason, an autosomal disease implies that the gene that causes the disease will be present in the autosomes, and both genders are usually clinically affected. In X-linked conditions, such as hemophilia, the gene that causes the disease is in sexual chromosome $\mathrm{X}$ and it affects predominantly males ${ }^{1}$.

Diseases caused by a single gene in a specific locus are known as monogenic and follow a Mendelian inheritance pattern. An "autosomal dominant" disease occurs when a mutated allele produces the phenotype in spite of the other normat allele. On the other hand, "autosomal recessive" inheritance is observed when both chromosomes display the mutated allele; only homozygous individuals have the disease ${ }^{3}$.

\section{PENETRANCE AND EXPRESSIVITY}

Penetrance is defined as the percentage of individuals with a particular genotype that expresses the expected phenotype. When a genotype fails to produce the expected phenotype, this is known as "incomplete penetrance" . Another related concept is "expressivity", which is defined as the level of expression of a trait determined by a gene. "Var iable expressivity" represents the expression spectrum of a specific genotype. Both incomplete penetrance and variable expressivity result from gene interaction effects and environmental effects, which can alter or partially or totally suppress the effect of a particular gene and, therefore, the sole presence of an altered gene does not warrant its expression. The phenotype is the result of a genotype that is expressed in a specific environment, i.e. each genotype can produce several phenotypes according to environmental conditions and interactions with other genes where the development occurs ${ }^{1}$.

\section{Example applied to oncology}

The $B R C A$ gene is a tumor-suppressor gene and is responsible for $60 \%$ of hereditary breast and ovarian cancer cases. 
This gene takes care of DNA double-strand rupture repair, and is inherited in an autosomal dominant form, i.e. there is $50 \%$ risk that the offspring will inherit the mutant gene from affected parents. However, even if there is one affected allele, it will require the other allele to become damaged throughout life for cancer to be produced, which is known as the Knudson or two-hit theory (which will be explained later).

Penetrance of this gene is high but incomplete. Between 41 and $90 \%$ of people who inherit a mutation develop cancer sometime in their lifetime ${ }^{8}$. Expressivity is variable: some people develop breast cancer, others ovarian cancer and, in a lesser proportion, cancer in other organs such as the pancreas and the peritoneum. In males, prostate cancer is more common, although they can also develop breast cancer. It should be noted that there will also be patients who will develop more than one malignancy throughout their lives, and there is risk for contralateral cancer (64\%) and ovarian cancer (44\%) after a first breast cancer.

The risk of cancer in BRCA-mutation carriers increases with age owing to incomplete penetrance and variable expressivity, but the development and onset of cancer cannot be accurately predicted ${ }^{3}$.

\section{MUTATIONS AND POLYMORPHISMS}

Changes in genetic information that are not explained by preexisting genetic variability recombination are known as "mutations". Mutations can be alterations in the number of structure of chromosomes or the result of changes in the DNA sequence, e.g. point mutations (changes or substitutions of one base for another) ${ }^{2}$.

Mutations are the source of evolution as they provide the raw materials for it to be carried out. Without mutations, genes would only exist in a single form and organisms would not be able to evolve and adapt to environmental changes?

Polymorphisms are genetic variants present in more than $1 \%$ of the population, while mutations are present in less than $1 \%$. Variants of a single nucleotide are known as single nucleotide polymorphisms (SNP), and are distinguished from point mutations by their frequency in the population ${ }^{3}$.

Table 1. Main types of mutations $\mathbf{s}^{1,5,17-18}$

\begin{tabular}{|c|c|}
\hline Type of mutation & Definition \\
\hline $\begin{array}{l}\text { Substitution } \\
\text { of one base }\end{array}$ & $\begin{array}{l}\text { Changes the nitrogenous base of a single nucleotide of the original DNA for another different one. } \\
\text { Example: g.45576A>C, changes an adenine for a cytosine at genomic position } 45576 \text { of the gene. }\end{array}$ \\
\hline \multirow[t]{2}{*}{ Insertion } & One or more nucleotides added in the original DNA sequence. \\
\hline & $\begin{array}{l}\text { Example: g.5756_5757insAGG, an insertion of the AGG nucleotides between positions } 5756 \text { and 5757, } \\
\text { generating an increase of three bases in the gene sequence. }\end{array}$ \\
\hline \multirow[t]{2}{*}{ Deletion } & Elimination of one or more nucleotides in the DNA sequence. \\
\hline & Example: g.120_123del, a loss of nucleotides 120 to 123 of the gene sequence. \\
\hline \multirow[t]{2}{*}{ Frameshift } & $\begin{array}{l}\text { Insertion or deletion of a number of nucleotides in the DNA (which is not divisible by three) that } \\
\text { affects the original traduction of the protein. }\end{array}$ \\
\hline & $\begin{array}{l}\text { Example: c. } 288 \text { 289dupCC (p.Arg97Profs*23) nucleotide } 288 \text { and } 289 \text { are duplicated (CC) resulting } \\
\text { in a change of amino acid arginine } 97 \text {, which is the first amino acid that changes for proline } \\
\text { creating a new reading frame ending at stop codon in position } 23 .\end{array}$ \\
\hline \multirow{2}{*}{$\begin{array}{l}\text { Expansion by } \\
\text { trinucleotide } \\
\text { repetition }\end{array}$} & $\begin{array}{l}\text { Repeated sequence of three nucleotides that progressively increases in quantity, potentially altering } \\
\text { the size of a gene. }\end{array}$ \\
\hline & $\begin{array}{l}\text { Example: c.53GCA[80], an increase in the number of repeated GCA (the } 3 \text { nucleotides repeated } \\
80 \text { times) in the encoding sequence of the gene. }\end{array}$ \\
\hline \multirow[t]{2}{*}{ Chromosomal } & $\begin{array}{l}\text { Alters the number or structure of one or more chromosomes, thus affecting many genes that } \\
\text { generate important phenotypical changes. }\end{array}$ \\
\hline & Example: $47, X Y,+21$, trisomy 21 , presence of an extra chromosome 21 . \\
\hline \multirow[t]{2}{*}{ Genomic } & Alters the haploid number of the species causing polyploidy. \\
\hline & Example: $69, \mathrm{XXX}$, triploidy, presence of $3 \mathrm{n}$, additional haploid complement. \\
\hline \multirow[t]{2}{*}{ Missense } & $\begin{array}{l}\text { Changes the wild type amino acid codon for another different one, thus altering the function } \\
\text { of the protein. }\end{array}$ \\
\hline & Example: c.4576A>C; p.Leu126Arg, the change of adenine for cytosine causes that wild type amino acid. \\
\hline \multirow[t]{2}{*}{ Nonsense } & $\begin{array}{l}\text { Changes the wild type amino acid codon for a stop codon, which causes premature termination } \\
\text { of the protein, leaving it without function. }\end{array}$ \\
\hline & $\begin{array}{l}\text { Example: c. } 4576 \mathrm{~A}>\mathrm{X} \text {; p.Leu126*, the change of adenine for another nucleotide causes the amino } \\
\text { acid leucine to change for a protein termination codon. }\end{array}$ \\
\hline \multirow[t]{2}{*}{ Silent } & $\begin{array}{l}\text { Change an encoding codon for another synonym; therefore, the amino acid sequence of the protein } \\
\text { is not altered. }\end{array}$ \\
\hline & $\begin{array}{l}\text { Example: c. } 4576 \mathrm{~A}>\mathrm{C} \text {; } \mathrm{p} . \text { Leu126=, in spite of the change of adenine for cytosine in the gene sequence, } \\
\text { the new codon encodes for the same leucine amino acid. }\end{array}$ \\
\hline
\end{tabular}




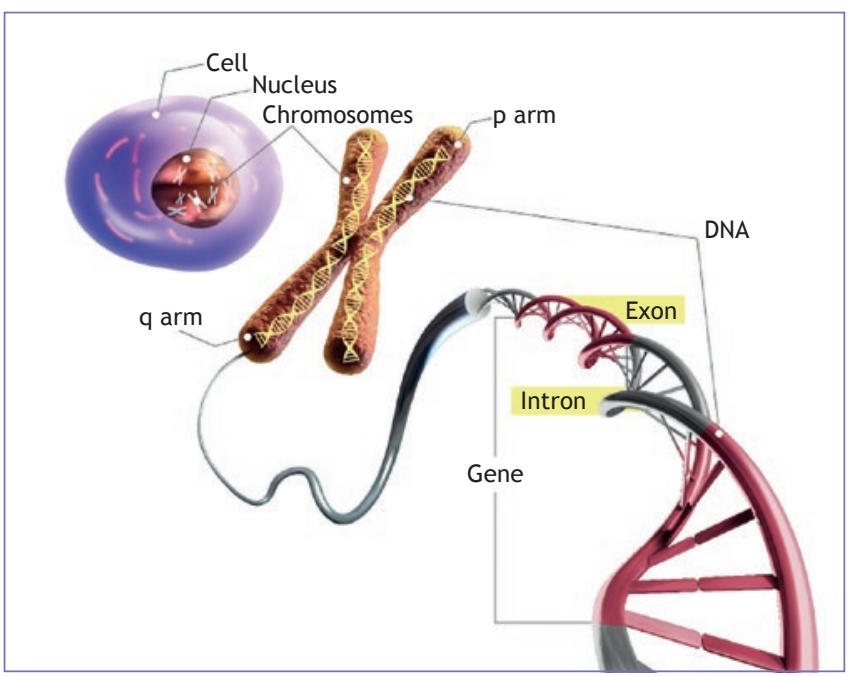

Figure 1. Structure and localization of a gene.

Mutations can originate in any cell and at any stage of the cell cycle. If the mutation is produced in "somatic cells" (any cell but gametes), these cells produce identical daughter cells, which results in the mutation only being detectable in cells descending from the original cell where the mutation was initiated ${ }^{2}$. If a mutation occurs in "germ cells" (in any of the gametes: ovule[s] or spermatozoid[s]), its effects are likely to be immediately expressed in the offspring ${ }^{2}$; this mutation is present in all cells of an individual's body ${ }^{3}$. Table 1 illustrates the different types of mutations, as well as examples of nomenclature for each case.

\section{CANCER GENES}

A group of genes are the main regulators of cell cycle and cell division and death processes. Mutations in these genes are mainly responsible for the development of cancer ${ }^{3}$.

In general, mutations occurring in genes that promote cell growth and division are dominant, since it only takes a single cell of the gene to be mutated for its effect to be produced; these genes are known as "oncogenes". In healthy cells, oncogenes' non-mutated versions are known as "proto-oncogenes", which, when mutated, turn into oncogenes and contribute to the development of cancer $^{1}$.

Some genes repress cell growth and division when inactivated by recessive mutations, stimulate cell division. This effect requires both gene copies to be mutated in order to block cell division inhibition; these genes are known as "tumor-suppressor genes". In this way, an organism can inherit a defective copy of the gene (heterozygous status) and not develop the disease since the other allele is wild-type (normal). However, heterozygous individuals are predisposed to develop cancer because wild-type allele inactivation is the only factor required to eliminate tumor-suppressor activity, a phenomenon known as "loss of heterozygocity" (LOH) ${ }^{1}$.

There is another group of genes called "DNA repair genes", usually tumor suppressor genes, which correct errors during cell division. Mutations in these genes making cells prone to accumulate mutational errors associated with several types of cancer (colorectal, endometrial and gastric cancer) ${ }^{1}$.

\section{Examples applied to oncology}

An example of an oncogene is the KRAS gene; having a proto-oncogene like this one mutated confers poor prognosis for tumors. It has been studied in colon cancer and lung cancer, among others; if it is mutated, chemotherapy with cetuximab or panitumumab is particularly not recommended owing to the low response rate.

With regard to tumor-suppressor genes, there are the mis match DNA-repair genes and $M L H 1$, responsible for $90 \%$ of Lynch syndrome or hereditary non-polyposis colorectal can cer, an autosomal-dominant syndrome of variable expressiy ity and incomplete penetrance. Although the most common cancer is in the colon, there is also risk for cancer in other organs such as the stomach, small intestine, pancreas, kidney, endometrium, and ovary. It occurs at 50 years of age on ayerage in the form of adenocarcinomas, predominantly in the proximal colon. Patients with this mutation have $52-82 \%$ of risk of developing cancer throughout their lives ${ }^{9}$. The $M \mathrm{MHZ}^{2}$ and $\mathrm{MLH} 1$ genes correct mismatch errors during DNA replication; when mutated, they promote other genes' alteration ${ }^{3}$.

\section{CANCER IS A GENETIC DISEASE}

Normal cells carry out several processes in response to internal and external (stimulating or inhibitory) signals: they grow, divide, maturate, and die. In a cancer cell, some of these signals are interrupted, which makes the cell proliferate at an abnormally higher velocity owing to the loss of response to normal control mechanisms, in this way modifying the original shape and ultimately producing an abnormal cell mass.

Cancer arises due to DNA mutations that alter genes as sociated with cell-division regulation. Ionizing radiation and chemical substances are carcinogenic due to sometimes they break DNA at one or two of its strands, activating an oncogene. Viruses such as human papilloma virus produce cancer because they carry oncogenes that are able to confer immortality to the cells they infect. Other cancers are associated with chromosomal defects; in chronic myeloid leukemia there is a reciprocal translocation between chromosomes 9 and 22 that generates a hybrid $B C R-A B L$ gene with oncogenic activity. Other cancers are of the hereditary type, owing to the inheritance of mutated tumor-suppressor genes ${ }^{1}$.

Most tumors have dozens of point mutations in several genes, and some cancers may have more than 200 mutations, with $95 \%$ of them being point mutations. However, many of these mutations are deemed to be "passenger mu tations" and do not confer a selective growth advantage, whereas a few are "driver mutations", i.e. they promote tumorigenesis. A typical tumor has 2-8 driver mutations that are related to signaling pathways that regulate cell destiny, survival, and genomic maintenance processes ${ }^{10}$.

\section{Example applied to oncology}

Retinoblastoma is an autosomal-dominant disease caused by an alteration in tumor-suppressor gene RB1. Knudson's Hypothesis or double-hit theory explains the genetic basis of this cancer. Knudson proposed that retinoblastoma is caused by two different genetic defects and both have to occur for cancer to develop. In cases where the retinoblastoma 
is unilateral, a single cell suffers two successive mutations. In cases of bilateral retinoblastoma both eyes are prone to cancer development, Knudson proposed that the patient inherits one of the two mutations (one hit) in all cells of the both eyes, second mutation in one eye-cell (two hits) is required to cancer development. In cases of unilateral retinoblastoma a single cell suffers two successive mutations (two hits). It should be noted that in these hereditary cases there is also risk for other type of cancers such as sarcoma, osteosarcoma, and melanoma ${ }^{1}$.

\section{CLASSIFICATION OF CANCER BASED ON ITS GENETIC ORIGIN}

\section{Sporadic cancer}

Sporadic cancer results from acquired, sequential, and non-corrected accumulation of mutations in somatic cells. Activation of mutations in oncogenes and inactivation of tumor-suppressor genes are probably sporadic tumor's first events, in addition to other independent mutations in at least 4-5 genes ${ }^{11}$. Another characteristic is the age of presentation is as expected for the type of cancer, generally it does not affect relatives, and usually there are aggregated environmental risk factors ${ }^{12}$.

\section{Hereditary cancer vs. hereditary cancer}

Familial cancer occurs in several members of one family. However, it is not possible to recognize inheritance patterns, usually there are no mutations in hereditary cancer genes, and an increased risk for the development of cancer is known to exist for relatives ${ }^{13}$.

\section{Hereditary cancer}

Hereditary cancer affects several members of a family and it is possible for inheritance patterns to be found. Generally, it occurs in people younger than expected for the type of cancer; these are more aggressive cancers and can be suspected based on clinical features. In hereditary cancers, it is important for germ mutations in one of the alleles of genes with high susceptibility for cancer to be identified. It is important to identify germline mutations in genes with high penetrance. For example, BRCA1, BRCA2, PALB2, CHEK2, TP53 and PTEN in hereditary breast and ovarian cancer ${ }^{11,14}$.

\section{GENETIC COUNSELING IN ONCOLOGY}

Genetic counseling consists in offering information and guidance to the index case and his/her family about the role of genes and the possibility of their offspring inheriting the cancer risk, to explain international recommendations on currently available follow-up and even therapeutic and surgical strategies, as well as medical uncertainties and the available support to solve psychosocial problems. Finally, the benefits and limitations of molecular testing should be explained ${ }^{15}$.

The risks for predisposition to cancer can vary among families due to the intervention of other modifier genes or the lifestyle $\mathrm{e}^{15,16}$.
Genetic counseling is an essential part of cancer diagnosis and diagnosis and should be carried out by a medical geneticist in Mexico. Adequate genetic counseling should be carried out before and after a molecular test is indicated ${ }^{15}$.

\section{CONCLUSIONS}

Basic clinical genetics concepts were introduced, including topics about mutations, polymorphisms, nomenclature notions, types of inheritance, as well as some interesting applications in the fields of pharmacogenetics, oncogenesis, hereditary cancers, and genetic counseling, which in future issues will be addressed in depth. Knowledge of the principles of genetics applied to clinical oncology will enable a comprehensive management of the patient and better une derstanding of genetic studies in the oncology practice.

\section{ACKNOWLEDGEMENTS}

We thank Dr. Silvia Vidal Millán for her valuable comments in the preparation of the present manuscript.

\section{REFERENCES}

1. Pierce BA. Fundamentos de genética. Conceptos y relaciones. Editorial Médica Panamericana; 2011.

2. Gardner EJ. Principios de Genética. Editorial LimusaWiley; 1998.

3. Nussbaum RL. Thompson \& Thompson, Genetics in Medicine. Editorial Saunders; 2004

4. Eiberg $\mathrm{H}$, Mohr J. Assignment of genes coding for brown eye colour (BEY2) and brown hair colour (HCL3) on chromosome 15q. Eur J Hum Genet. 1996;4:237-41.

5. Salazar-Montes A. Biología Molecular. Fundamentos y aplicaciones en las ciencias de la salud. Editorial Mc Graw Hill; 2013.

6. Contreras AV, Monge-Cazares T, Alfaro-Ruiz L, et al. Resequencing haplotype construction and identification of novel variants ofCYP2D6 in Mexican Mestizos. Pharmacogenomics. 2011;12:745-56.

7. Hoskins JM, Carey LA, McLeod HL. CYP2D6 and tamoxifen: DNA matters in breast cancer. Nat Rev Cancer. 2009;9:576-86.

8. National Comprehensive Cancer Network. NCCN Clinical Practice Guidelines in Oncology: Genetic/Familial High-Risk Assessment: Breast and Ovarian, 2017. Available at: https://www.nccn.org/professionals/o physician_gls/f_guidelines.asp (Accessed Jan 15, 2017).

9. National Comprehensive Cancer Network. NCCN Clinical Practice Guidelines in Oncology: Genetic/Familial High-Risk Assessment: Colorectal, 2017. Available at: https://www.nccn.org/professional\$ / physician_gls/f_guidelines.asp (Accessed Jan 15, 2017).

10. Vogelstein B, Papadopoulos N, Velculescu VE, Zhou S, Diaz LA Jr, Kinzler KW. Cancer genome landscapes. Science. 2013;339:1546-58.

11. Kenemans P, Verstraeten RA, Verheijen RHM. Oncogenic pathways in hereditary and sporadic breast cancer. Maturitas. 2004;49:34-43.

12. Clemons $M$, Goss P. Estrogen and the risk of breast cancer. N Engl $f$ Med. 2001;344:276-85.

13. American Cancer Society. Genes and Cancer. Available at: http://a www.cancer.org/acs/groups/cid/documents/webcontent/002550-pdf.pdf (Accessed December 31, 2016).

14. ACOG Committee opinion no. 634: Hereditary cancer syndromes and risk assessment. Obstet Gynecol. 2015;125:1538-43.

15. Vidal Millán S. Cáncer de Mama Hereditario: Identificación y Elección de Pacientes para Estudio Molecular de los Genes BRCA. Cancerología. 2008;3:51-61.

16. Ochoa-Carrillo FJ, Millán SV. [Importance of genetic counseling and molecular diagnosis testing in families at high risk for cancer]. Cir Cir. 2006;74:137-42.

17. Solari JA. Genética Humana. Fundamentos y aplicaciones en Medicina. Médica Panamericana, Cuarta edición; 2011.

18. Sequence Variant Nomenclature. Version 15.11. Available at: http:// varnomen.hgvs.org/recommendations/protein/variant/frameshift / (Accessed January 26, 2017). 